\title{
Transverse maxillary and mandibular growth during and after Bionator therapy: Study with metallic implants
}

\author{
André da Costa Monini¹, Luiz Gonzaga Gandini Júnior², Luiz Guilherme Martins Maia³, Ary dos Santos-Pinto
}

Introduction: This study evaluated posteroanterior cephalograms before and after treatment and long term follow-up of Class II division 1 patients treated with bionator. Objective: The objective was to demonstrate the transverse growth of maxilla and mandible during and after bionator therapy. Methods: Measurement of transverse dimensions between posterior maxillary and mandibular implants, as well as the distances between the buccal, gonial and antegonial points were recorded. Measurements were analyzed at three periods: $\mathrm{T}_{1}=$ before bionator therapy, $\mathrm{T}_{2}=$ after bionator therapy and $\mathrm{T}_{3}$ $=5.74$ years after $\mathrm{T}_{2}$. Results: There was statistically significant transverse increase due to growth and/or treatment for all variables, except for the distance between the anterior maxillary implants. Conclusions: During the study period only the anterior maxillary area did not show transverse growth.

Keywords: Activator appliances. Angle Class II malocclusion. Maxillofacial development.

Introdução: esse estudo envolve a avaliação de telerradiografias posteroanteriores pré- e pós-tratamento com Bionator, bem como, em longo prazo, de pacientes Classe II divisão 1. Objetivo: o objetivo desse trabalho é demonstrar o crescimento transversal da maxila e mandíbula durante e após o uso do Bionator. Métodos: as mensurações das distâncias transversais entre os implantes posteriores da maxila e mandíbula, bem como as das distâncias entre os pontos jugal, gônio e antigônio, foram tomadas em três tempos: $\mathrm{T}_{1}$, antes da terapia com Bionator; $\mathrm{T}_{2}$, após a terapia como Bionator; e $\mathrm{T}_{3}$, 5,74 anos após $\mathrm{T}_{2}$. Resultados: ocorreu aumento transversal estatisticamente significativo por crescimento e/ou por tratamento em todas as variáveis estudadas, com exceção da distância entre os implantes anteriores da maxila. Conclusões: durante o período do estudo, somente a região anterior da maxila não apresentou crescimento transversal.

Palavras-chave: Aparelhos ativadores. Má oclusão de Angle Classe II. Desenvolvimento maxilofacial.

${ }^{1}$ Specialist and Master in Orthodontics UNESP-Araraquara.

${ }^{2}$ Professor, School of Dentistry of Araraquara, UNESP. Assistant Professor, Baylor College of Dentistry, Dallas, Texas, USA.

${ }^{3}$ Master and Doctorate student in Orthodontics UNESP- Araraquara.

${ }^{4}$ Professor, School of Dentistry of Araraquara, UNESP.

\footnotetext{
How to cite this article: Monini AC, Gandini Júnior LG, Maia LGM, SantosPinto A. Transverse maxillary and mandibular growth during and after Bionator therapy: Study with metallic implants. Dental Press J Orthod. 2013 May-June;18(3):72-9.

Submitted: January 04, 2010 - Revised and accepted: October 20, 2010

» The authors report no commercial, proprietary or financial interest in the products or companies described in this article.

Contact address: Luiz Gonzaga Gandini Júnior

Av. Casemiro Perez, 560 - Vila Harmonia - Araraquara/SP - Brazil

CEP: 14.802-600 - E-mail: luizgandini@uol.com.br
} 


\section{INTRODUCTION}

Few studies evaluating the transverse growth of the face were carried out so far, especially regarding sagittal growth. This is due to problems such as difficulty on identification and consequent reproducibility of cephalometric points, ${ }^{18,21}$ standardization of the head positioning, ${ }^{20,11}$ radiographic magnification $^{9,11,15,27}$ and standardization of the sample. ${ }^{19}$ In the last years, some studies assessed the facial skeletal growth without interference of functional orthopedic appliances. ${ }^{9}, 10,13,16,17,25$ Several studies showed the potential of increase on transverse growth of the jaws by the use of functional appliances s, $^{1,12,14,23,26}$ and three of them ${ }^{12,14,26}$ followed longitudinally the patients after treatment, but without radiographic evaluation. The longitudinal examination using metallic implants carried out so far refers to Class I patients with or without treatment $t^{4,5,10,17}$ or to mixed samples. ${ }^{16}$

The cephalometric studies in teleradiographs with metallic implants proved to be the most efficient method to longitudinally assess the craniofacial growth ${ }^{3,5}$ due to the difficulty of identification of cephalometric points and remodeling that occurs on the surface of the jaws. The objective of the present study is to evaluate the maxillary transverse growth and its relation to the treatment, through posteroanterior radiographs, during 6 years after the use of Balters' bionator in patients with metallic implants.

\section{MATERIAL AND METHODS}

The sample consisted of 25 patients that used bionator ( 15 boys and 10 girls), participants on a prior study ${ }^{1}$ and treated in the Department of Orthodontics at the School of Dentistry of Araraquara - Unesp. Each one of them presented skeletal Class II with mandibular retrusion, upper and lower incisors erupted or in eruption, overbite, no dental loss, absence of crowding and/or posterior cross bite. The subjects of the sample had metallic implants inserted in the maxilla (four implants) and mandible (three implants), according to proposed by Björk. ${ }^{6,7}$ From the original sample of 25 patients (mean age of 9.2 years), it was possible to obtain long term radiographs of 13 patients ( 9 boys and 4 girls) with mean age of 16.95 years. The other patients could not be contacted. On the final sample, one patient did not present the posterior implants on the maxilla in $\mathrm{T}_{3}$ and on the mandible in $\mathrm{T}_{1}$, other patient did not present one anterior implant in $\mathrm{T}_{3}$ and another patient did not present one of the posterior implants on the mandible. Table 1 shows age and gender of the sample and Table 2 characterizes the sample.

Lateral and posteroanterior teleradiographs were obtained in three time periods: $\mathrm{T}_{1}$ at the beginning of treatment with bionator, $\mathrm{T}_{2}$ at the end of the bionator therapy and $\left(\mathrm{T}_{3}\right) 5.74$ years, on average, after $\mathrm{T}_{2}$. The teleradiographs were manually traced and the cephalometric points were digitized twice on Dentofacial Planner Plus (DFP Plus, version 2.0, Toronto, Ontario, Ca) by a single examiner and the digitalization mean was used for cephalometric measurements. The cephalometric points used on the posteroanterior teleradiographs are described on Table 3 and Figure 1.

The transverse growth was calculated by the transverse linear distance between the cephalometric points on the right and on the left. Corrections for magnification on transverse linear measurements were necessary before classifying the growth data, because although the posteroanterior teleradiographs had been taken with cephalostat, the radiographic magnification of the region of the metallic implants is different from the region of the acoustic meatus center plane because it is closer to the radiographic film, especially compared to the anterior implants on the maxilla. Another reason for correction is that, with the facial growth, maxilla move forward carrying together the metallic implants making them closer to the radiographic film. These variations on radiographic magnification were mathematically corrected by a combination of information of lateral and posteroanterior teleradiograph using correction method recommended by Hsiao et al. ${ }^{15}$ A reference system, comprised by Frankfurt's horizontal plane and a vertical line perpendicular from the Porion, built in each lateral teleradiograph allowed the calculation of distance from the position of the implants mean to the acoustic meatus center plane (Fig 2).

With these measures it was possible to calculate the radiographic magnification on the region of metallic implants for each patient based on the formula described by Hsiao et al: ${ }^{15}$ Inter-implants real distance $=$ inter-implants radiographic distance $\mathrm{x}$ focusear rods distance + ear rods-implant distance / distance focus-film (Fig 3). 
Table 1 - Characteristics of the studied sample.

\begin{tabular}{|c|c|c|c|c|}
\hline \multirow{3}{*}{ Individuals } & \multirow{3}{*}{$n$} & $\mathrm{~T}_{1}$ & $\mathbf{T}_{2}$ & $T_{3}$ \\
\hline & & Mean (years) & Mean (years) & Mean (years) \\
\hline & & $\pm S D$ & \pm SD & \pm SD \\
\hline Male & 9 & $9.25 \pm 1.39$ & $11.08 \pm 1.28$ & $16.99 \pm 1.62$ \\
\hline Female & 4 & $9.55 \pm 1.01$ & $11.52 \pm 1.7$ & $16.86 \pm 2.17$ \\
\hline Total & 13 & $9.34 \pm 1.25$ & $11.21 \pm 1.36$ & $16.95 \pm 1.71$ \\
\hline
\end{tabular}

Table 2 - Sagittal and vertical angular cephalometric measures

\begin{tabular}{cccc}
\hline MEASURES & $\mathrm{T}_{1}$ & $\mathrm{~T}_{2}$ & $\mathrm{~T}_{3}$ \\
& Mean (years) $\pm \mathrm{SD}$ & Mean (years) \pm SD & Mean (years) \pm SD \\
SNA & $82.92 \pm 4.0^{\circ}$ & $81.53 \pm 3.9^{\circ}$ & $81.26 \pm 4.4^{\circ}$ \\
SNB & $76.75 \pm 3.5^{\circ}$ & $77.56 \pm 3.9^{\circ}$ & $78.20 \pm 4.3^{\circ}$ \\
ANB & $6.17 \pm 1.9^{\circ}$ & $3.96 \pm 2.3^{\circ}$ & $3.05 \pm 2.6^{\circ}$ \\
SN.GOMe & $32.91 \pm 5.3^{\circ}$ & $33.57 \pm 5.9^{\circ}$ & $31.73 \pm 6.4^{\circ}$ \\
\hline FMA & $23.49 \pm 3.8^{\circ}$ & $23.86 \pm 4.4^{\circ}$ & $22.33 \pm 5.4^{\circ}$ \\
SN-ANS-PNS & $5.98 \pm 2.7^{\circ}$ & $6.78 \pm 4.2^{\circ}$ & $6.43 \pm 3.5^{\circ}$ \\
\hline
\end{tabular}

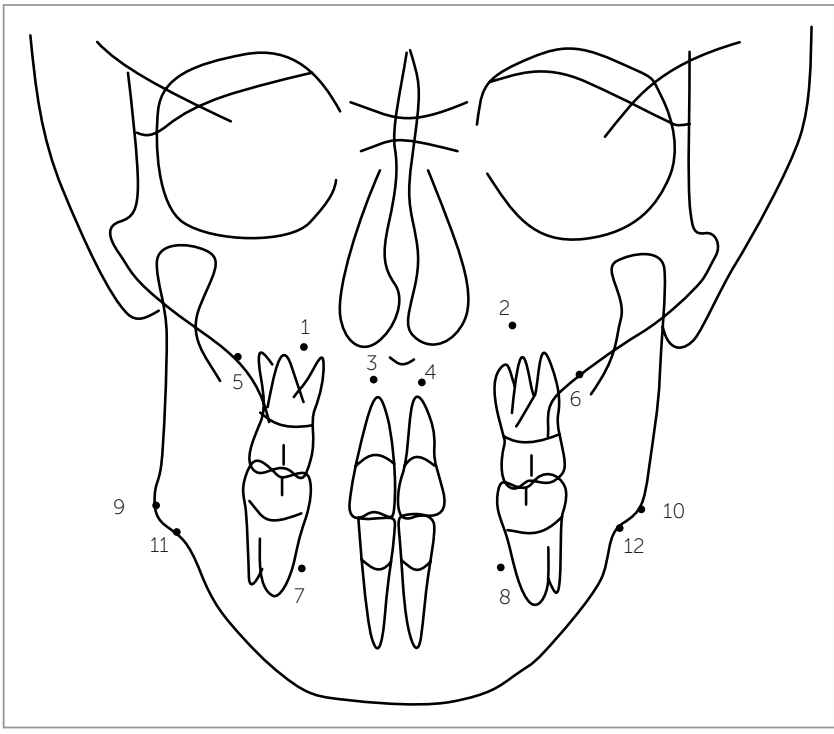

Figure 1 - Cephalometric points digitized on the posteroanterior teleradiograph. Table 3 identifies each cephalometric point.

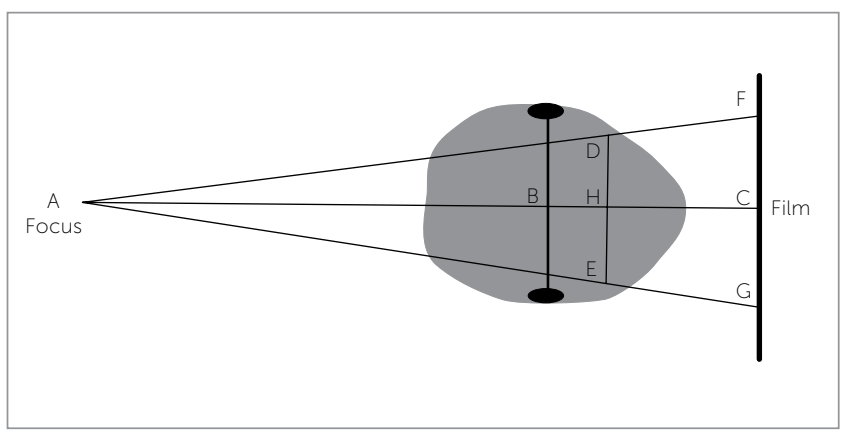

Table 3 - Cephalometric points digitized on the posteroanterior teleradiograph.

\begin{tabular}{|c|c|}
\hline $\begin{array}{l}\text { CEPHALOMETRIC } \\
\text { POINTS }\end{array}$ & DESCRIPTION \\
\hline 1) $\mathrm{R}$ PIMX & Right posterior implant of the maxilla \\
\hline 2) LPIMX & Left posterior implant of the maxilla \\
\hline 3) $\mathrm{R}$ AIMX & Right anterior implant of the maxilla \\
\hline 4) L AIMX & Left anterior implant of the maxilla \\
\hline 5) $\mathrm{RJ}$ & $\begin{array}{l}\text { Intersection of the right maxillary tuber with the } \\
\text { zygomatic wall }\end{array}$ \\
\hline 6) $\mathrm{LJ}$ & $\begin{array}{l}\text { Intersection of the left maxillary tuber with the } \\
\text { zygomatic wall }\end{array}$ \\
\hline 7) R PIMD & Right posterior implant of the mandible \\
\hline 8) L PIMD & Left posterior implant of the mandible \\
\hline $\begin{array}{l}\text { 9) } \mathrm{R} \text { Go } \\
\text { (Right Gonion) }\end{array}$ & $\begin{array}{l}\text { Most posterior and inferior point of the right } \\
\text { gonial angle }\end{array}$ \\
\hline $\begin{array}{l}\text { 10) L Go } \\
\text { (Left Gonion) }\end{array}$ & $\begin{array}{l}\text { Most posterior and inferior point of the left gonial } \\
\text { angle }\end{array}$ \\
\hline $\begin{array}{l}\text { 11) } \mathrm{R} \mathrm{Ag} \\
\text { (Right Antegonion) }\end{array}$ & Deeper point of the right antegonial notch \\
\hline $\begin{array}{l}\text { 12) } \mathrm{L} \text { Ag } \\
\text { (Left Antegonion) }\end{array}$ & Deeper point of the left antegonial notch \\
\hline
\end{tabular}

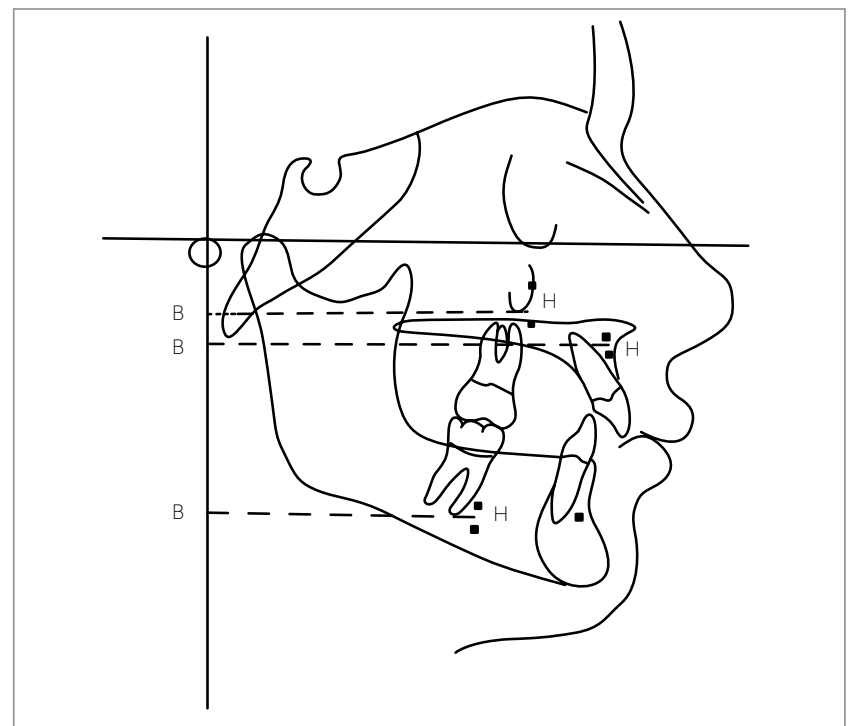

Figure 2 - Traced line shows the calculation of distance from the position of implants (mean point between implants) to the acoustic meatus center plane.

Figure 3 - AB: Distance focus-olive; $\mathrm{BH}$ : ear rods-implant distance; $\mathrm{AC}$ : focusfilm distance; DE: inter-implants real distance (posterior inter-implants of the maxilla, anterior inter-implants of the maxilla and posterior inter-implants of the mandible); FG: inter-implants. radiographic distance (Source: Hsiao et al. ${ }^{15}$ ). 
The following transverse measurements were performed:

" R PIMX - L PIMX: Distance inter-posterior implants of the maxilla.

" R AIMX - L AIMX: Distance inter-anterior implants of the maxilla.

" RJ - LJ: Distance inter-jugal, in relation to the maxilla width.

» R PIMD - L PIMD: Distance inter-posterior implants of the mandible.

"R Go - L Go: Distance inter-gonial, in relation to mandibular width on point Go.

» $\mathrm{R}$ Ag - L Ag: Distance inter-antegonial, in relation to mandibular width on point Ag.

\section{Statistical analysis}

The mean and standard deviation were calculated for each variable. The different variables presented normal distribution and the Student's $t$ test was used to evaluate the significance of the changes during evaluation periods $\left(\mathrm{T}_{2}-\mathrm{T}_{1}, \mathrm{~T}_{3}-\mathrm{T}_{2}\right.$, and $\left.\mathrm{T}_{3}-\mathrm{T}_{1}\right)$. The level of significance used was $\mathrm{p} \leq 0.05$. All calculations were performed with SPSS for Windows (version 10.0, SPSS Inc., Chicago, Ill).

\section{Method error}

To evaluate the error on the localization of cephalometric points and digitalization procedures all tracings were digitalized again after two weeks by the same examiner. The random error was evaluated using Dahlberg's formula and the systematic errors were evaluated using paired $t$ test. The method random error (Dahlberg's formula) did not exceed $0,33 \mathrm{~mm}$. The paired $t$ test did not show statistically significant systematic error.

\section{RESULTS}

Table 4 shows the transverse dimension of the maxilla and mandible on the three periods of evaluation. Table 5 shows that there was statistically significant increase of the maxillary transverse distances on the region of anatomic cephalometric points (Go, Ag and J) and of implants in all evaluated periods, except for the region of anterior implants of the maxilla that did not show statistically significant growth at no time. The lowest gains obtained were on the distance between mandibular implants and the highest were found on the inter-gonial distance.

\section{DISCUSSION}

The size of the sample cannot be considered representative of the population in a statistical sense, on the other side, due to the use of metallic implants, a detailed analysis can provide information on the facial growth. ${ }^{16}$ Studies with posteroanterior radiographs present some limitations such as variability on the magnification of the projected transverse dimension,,$^{9,16,22}$ problem of standardization of the head positioning on the cephalostat ${ }^{16,22,25}$ due to slight up and down movements of the head and difficulty on identification of points. ${ }^{16,18,22}$

Table 4 - Means and standard deviation of the maxillary and mandibular dimension by period of evaluation.

\begin{tabular}{cccc}
\hline Variable & $\mathrm{T}_{1}$ & $\mathrm{~T}_{2}$ & $\mathrm{~T}_{3}$ \\
& Mean $\pm \mathrm{SD}$ & Mean $\pm \mathrm{SD}$ & Mean $\pm \mathrm{SD}$ \\
$\mathrm{R} \mathrm{Go}-\mathrm{LGO}$ & $82.37 \pm 4.8$ & $84.71 \pm 5.1$ & $91.04 \pm 5.5$ \\
$\mathrm{R} \mathrm{Ag}-\mathrm{LAg}$ & $75.56 \pm 5.5$ & $77.63 \pm 5.8$ & $81.05 \pm 5.6$ \\
$\mathrm{R} \mathrm{J}-\mathrm{LJ}$ & $57.46 \pm 2.0$ & $59.32 \pm 2.4$ & $63.01 \pm 2.8$ \\
\hline
\end{tabular}

Table 5 - Transverse alterations of the distances between implants and of the maxilla and mandible widths.

\begin{tabular}{|c|c|c|c|c|c|c|}
\hline \multirow{2}{*}{ Variable } & \multicolumn{2}{|c|}{$T_{2}-T_{1}$} & \multicolumn{2}{|c|}{$T_{3}-T_{2}$} & \multicolumn{2}{|c|}{$T_{3}-T_{1}$} \\
\hline & Mean \pm SD & $p$ & Mean \pm SD & p & Mean \pm SD & $p$ \\
\hline R PIMX - L PIMX & $1.27 \pm 0.5$ & $0.000 *$ & $2.52 \pm 1.5$ & $0.000 *$ & $3.77 \pm 1.6$ & $0.000 *$ \\
\hline R AIMX - LAIMX & $0.12 \pm 0.4$ & 0.356 & $-0.53 \pm 1.3$ & 0.209 & $-0.35 \pm 1.4$ & 0.414 \\
\hline R PIMD - L PIMD & $0.66 \pm 0.8$ & $0.027^{\star}$ & $0.83 \pm 1.2$ & $0.049 *$ & $1.49 \pm 1.6$ & $0.015 *$ \\
\hline R Go - L Go & $2.33 \pm 1.1$ & 0.000 * & $6.33 \pm 2.6$ & $0.000^{*}$ & $8.66 \pm 2.2$ & $0.000 *$ \\
\hline$R A g-L A g$ & $2.06 \pm 1.6$ & $0.001 *$ & $3.42 \pm 2.1$ & $0.000 *$ & $5.48 \pm 2.0$ & $0.000 *$ \\
\hline$R J-L J$ & $1.85 \pm 1.3$ & 0.000 * & $2.68 \pm 2.2$ & $0.000 *$ & $5.54 \pm 1.8$ & $0.000 *$ \\
\hline
\end{tabular}

* $=$ statistically significant values $p \leq 0.05$ 
The problem on identification of points is corrected when metallic implants are used, the variability of magnification was individually corrected for the distances between implants in each period of evaluation, but the problems of standardization of the head positioning are impossible to solve because slight movements of the head are inevitable, ${ }^{14}$ however, some studies ${ }^{11,20}$ did not find statistically significant differences among measures taken with up to $10^{\circ}$ of difference.

The study confirmed the increase of bone bases and evidenced that the maxillary growth was greater than the mandibular. ${ }^{1,10,17}$ The distance between posterior implants of the maxilla increased more than the distance between the anterior implants confirming the findings of other studies ${ }^{4,5,10,17}$ and showing that the maxillary growth on the posterior region was greater than the anterior besides confirming the existence of transverse growth until the studied age. The mean increase of the distance between posterior implants of the maxilla during all evaluated period, $\mathrm{T}_{1}-\mathrm{T}_{3}$, was of $3.77 \mathrm{~mm}$. Björk and Skieller ${ }^{5}$ found $3 \mathrm{~mm}$ increase from $10-11$ years to 21 years and in a previous study ${ }^{4}$ they found $2.8 \mathrm{~mm}$ from 11 to 19 years of age. The result in this work was a little higher, but considering the standard deviation the values are similar because they also observed great variability. ${ }^{5}$ The amount of maxillary transverse growth between the implants when compared to the increase related to Jugal point agrees with the present literature ${ }^{4,5}$ confirming the median palatine suture as the main site for the maxillary transverse growth and, less expressive, the bone apposition in other areas completing the transverse growth (Table 5).

The differential maxillary transverse increase regarding the anterior and posterior region implies in a transverse rotation between the sides. ${ }^{4,5,10,17}$ Our find- ings agree with other study ${ }^{10}$ about the posterior move of the maxillary transverse rotation center with aging in function of the immutability of the anterior maxillary transverse distance.

Table 6 shows that the annual growth of the posterior region of the maxilla was the greatest among the studies that used metallic implants. This result may be associated to the influence of the facial pattern since the patients with horizontal growth pattern present larger transverse facial dimensions when compared to other patterns, ${ }^{27}$ may be due to the fact that the sample is composed mostly by male that presents facial widths larger than female $9,17,24,25,28$ and/or stimulation of transverse growth by the use of bionator. ${ }^{1,8}$ During the treatment with bionator there was an increase of $1.85 \mathrm{~mm}$ on the distance RJ - LJ. A previous study ${ }^{19}$ showed $1.72 \mathrm{~mm}$ increase during the same period in Class II division 1 patients and $2.03 \mathrm{~mm}$ in Class I patients. This difference may be related to the therapy used because when comparing Class II our results were higher and when compared Class I they were lower, but it must be emphasized that Class II patients present the maxillary transverse dimension smaller than Class I patients. ${ }^{19}$ Besides, the remodeling of the Jugal point during this period was also greater than the presented by other works. ${ }^{2,9,13}$ The annual transverse increase between the maxillary implants calculated on the same period was $0.73 \mathrm{~mm}$. In one year of treatment with Frankel's appliance, a study ${ }^{8}$ showed $0.57 \mathrm{~mm}$ of increase in patients with age and gender distribution similar to the present study. It was concluded that the treatment was capable to increase the basal transverse distances of the maxilla. As the values of annual growth in the present study, were higher it is believed that the bionator also has the capacity to increase the maxillary bone base, ${ }^{1}$ although it is not clinically significant.

Table 6 - Annual changes ( $\mathrm{mm} /$ year) and standard deviation in transverse growth with metallic implants according to the location.

\begin{tabular}{|c|c|c|c|c|c|}
\hline Authors & Anterior of the maxilla & Posterior of the maxilla & Posterior of the mandible & $n$ & Age (years) \\
\hline Björk, Skieller ${ }^{4,5}$ & $0.12 \pm 0.06$ & $0.42 \pm 0.12$ & Did not report & 9 & 10 to 20 \\
\hline Korn, Baumrind ${ }^{17}$ & $0.15 \pm 0.11$ & $0.43 \pm 0.18$ & $0.28 \pm 0.15$ & 31 & 8.5 to 15.5 \\
\hline Gandini, Buschang ${ }^{10}$ & $-0.10 \pm 0.18$ & $0.27 \pm 0.13$ & $0.19 \pm 0.20$ & 13 & 13.9 to 16.7 \\
\hline Iseri, Solow ${ }^{16}$ & Did not report & Did not report & $0.13 \pm 0.06$ & 10 & 6 a 18 \\
\hline Marotta Araujo et al. ${ }^{1}$ & $-0.14 \pm 0.53$ & $0.40 \pm 0.17$ & $0.03 \pm 0.25$ & 14 & 8.9 to 9.9 \\
\hline Present study & $-0.04 \pm 0.18$ & $0.49 \pm 0.22$ & $0.18 \pm 0.18$ & 13 & 9.34 to 16.95 \\
\hline
\end{tabular}


During the bionator therapy, the presented mandibular basal transverse growth was $0.66 \mathrm{~mm}$. Another study, ${ }^{16}$ on the same period of evaluation, found 0,46 $\mathrm{mm}$ and despite not presenting similar sample to the present study, it could be assumed that the bionator has the ability of increasing the mandibular bone base, when used appropriately. This information was already reported by another study ${ }^{1}$ that did not find statistically significant mandibular transverse increase during one year of treatment with bionator, but observed higher value on the treated group. Evaluating the annual changes of growth on the two periods it is observed that on the stage of treatment with bionator the maxillary and mandibular basal transverse growth was $0.73 \mathrm{~mm} /$ year and $0.37 \mathrm{~mm} /$ year, respectively. After therapy, the normal growth showed $0.43 \mathrm{~mm} /$ year and $0.14 \mathrm{~mm} /$ year for maxilla and mandible showing the stimulation of growth with bionator (Figs 4 to 8 ). The mandibular basal transverse increase is a supposition, but at a dental and dentoalveolar matter it was already identified in studies with functional appliances. ${ }^{12,14,23,26}$ The width of the mandibular implants increased $0.18 \mathrm{~mm} /$ year, value similar to the one found previously ${ }^{10}$ in older Class I patients. This result may represent that Class II patients have lower potential of mandibular basal transverse growth even if treated at a young age, however some authors ${ }^{19}$ did not identify difference on the mandible between Class I and II patients.

After therapy with bionator, the remodeling on the Jugal point found by the present study was greater than the ones shown by several articles with similar period of observation..$^{2,9,13,19,27}$ Differently from the maxilla,

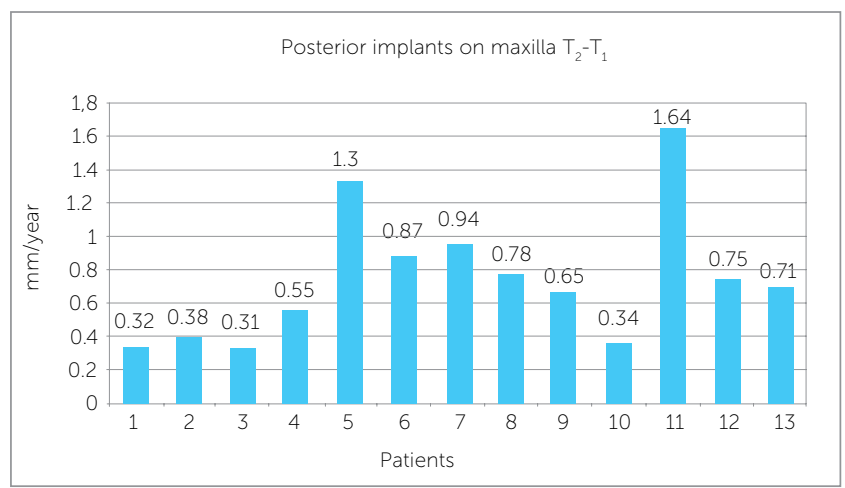

Figure 5 - Individual annual changes in transverse growth on the region of posterior implants of the maxilla during bionator therapy. the contribution of the basal growth on the mandibular transverse increase is lower than the remodeling ${ }^{10}$ (Table 5). Regarding the mandibular remodeling, after therapy with bionator, our results were lower than the ones presented by other works, ,2,9,19,27 and observing the increase of the distance R Ag-L Ag during therapy with bionator, the amount of remodeling was identical to one found in the same period $(2 \mathrm{~mm}),{ }^{9}$ but inferior to other works. ${ }^{2,19,27}$ However the values of annual growth obtained during the treatment were systematically higher (Fig 4).

The mandibular transverse distance, both on the region of Gonion and Antegonion, evaluated in $\mathrm{T}_{3}$, is lower than the presented by Lux et $\mathrm{al}^{19}$ evaluating 15 years old

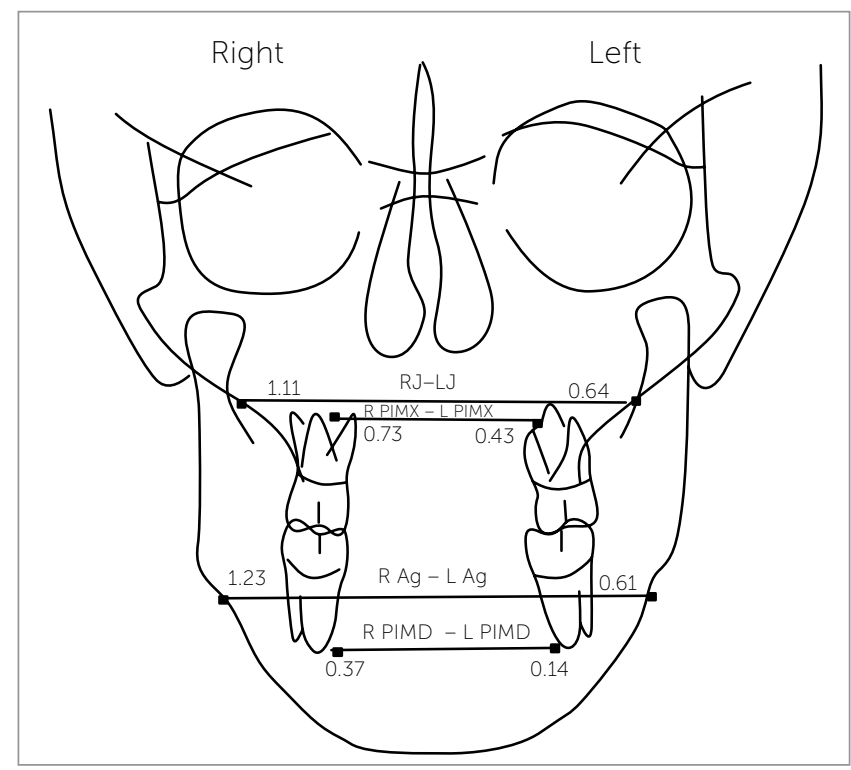

Figure 4 - Annual changes in transverse growth during bionator therapy (values on the right) and after bionator therapy (values on the left).

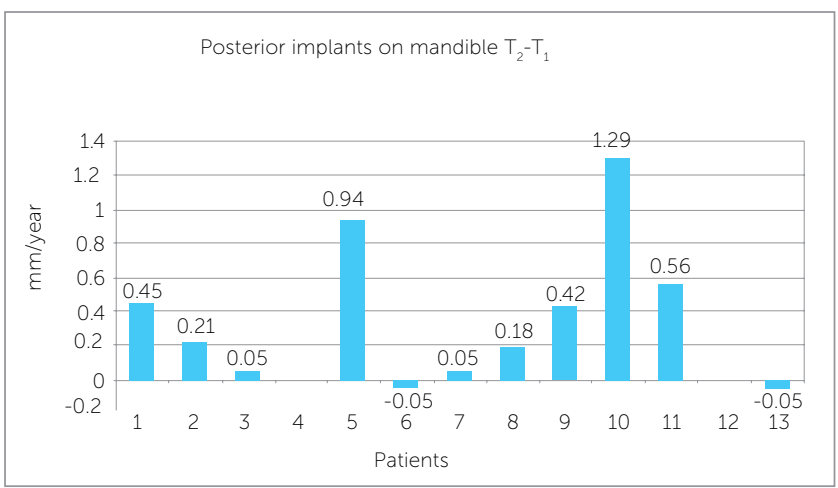

Figure 6 - Individual annual changes in transverse growth on the region of posterior implants of the mandible during bionator therapy. 
Class I or II patients. It was also lower than presented in other studies. ${ }^{2,13,27}$ Thus, our results suggest that the Class II patients, present mandibular transverse growth and dimensions lower that Class I patients, not confirming the result by Lux et al, ${ }^{19}$ although the found differences of size probably have little clinical meaning once they were not greater than $4 \mathrm{~mm}$. Besides, the gonial region showed wide remodeling during growth and it is the transverse dimension of the lower third of the face that presents greater growth and possibility of morphological variation. On Table 7 it can be noticed the influence of gender and malocclusion on the mandibular transverse growth since the lowest annual growths are related to studies evaluating female patients and/or with Class II malocclusion. Another aspect is that the comparison of normative values between the studies is not appropriated due to radiographic magnification. Some articles do not mention the correction and other do not describe appropriately the used methodology. Due to these problems some studies $^{9,27}$ suggest the use of proportion (JJ/AgAg) instead of normative values to minimize the problem although not solving it because some centers take posteroanterior radiographs with Frankfurt's plane parallel to the ground and others with Frankfurt plane inclined $35^{\circ}$ down.

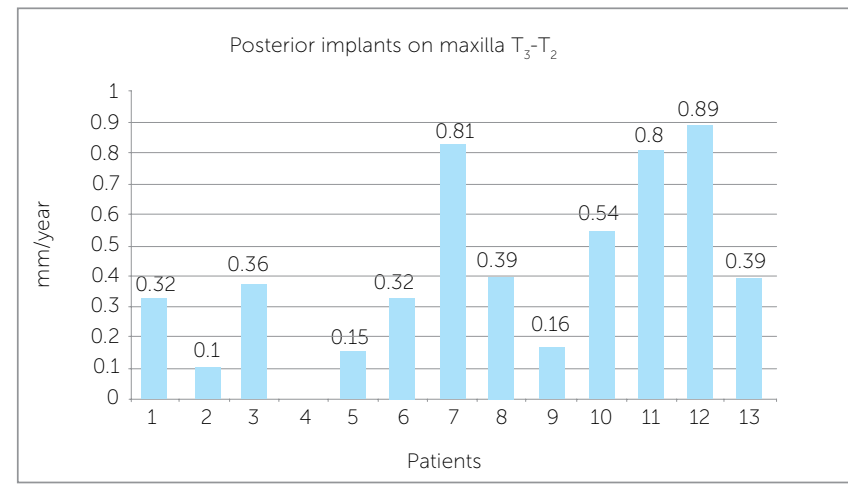

Figure 7 - Individual annual changes in transverse growth on the region of posterior implants of the maxilla after bionator therapy.

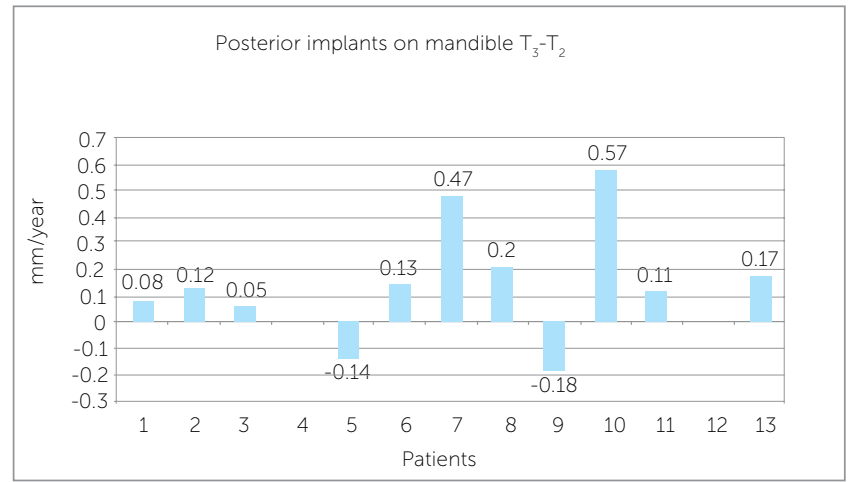

Figure 8 - Individual annual changes in transverse growth on the region of posterior implants of the mandible after bionator therapy.

Table 7 - Annual changes ( $\mathrm{mm} /$ year) in transverse growth of anatomic points according to the location.

\begin{tabular}{|c|c|c|c|c|c|c|}
\hline Author & $\mathbf{R} \mathbf{J}-\mathbf{L} \mathbf{J}$ & R Go - L Go & $\mathbf{R} \mathbf{A g}-\mathbf{L} \mathbf{A g}$ & Age (years) & Corrected magnification & Type of malocclusion \\
\hline Cortella et $\mathrm{a}^{9}$ & 0.58 & Not informed & 1.03 & 5 to 18 & Yes & 1 \\
\hline Snodell et al ${ }^{25}$ & 0.73 & 1.53 & Not informed & 6 to 18 & Not informed & 1 \\
\hline Hesby et $\mathrm{al}^{13}$ & 0.76 & 1.42 & 1.24 & 7.6 to 16.5 & Yes & I \\
\hline Yavuz et $a^{28}$ & 1.05 & Not informed & 1.98 & 10 to 14 & Not informed & 1 \\
\hline $\begin{array}{l}\text { Lux et al }{ }^{19} \\
\text { (boys) }\end{array}$ & 0.98 & 1.68 & 1.40 & 7.64 to 15.61 & Yes & I \\
\hline $\begin{array}{l}\text { Lux et a }\left.\right|^{19} \\
\text { (girls) }\end{array}$ & 0.66 & 1.37 & 1.21 & 7.6 to 15.66 & Yes & 1 \\
\hline $\begin{array}{l}\text { Lux et a }{ }^{19} \\
\qquad \text { (boys) }\end{array}$ & 0.65 & 1.54 & 1.15 & 7.49 to 15.6 & Yes & II \\
\hline $\begin{array}{l}\text { Lux et a }{ }^{19} \\
\qquad \text { (girls) }\end{array}$ & 0.61 & 1.36 & 1.13 & 7.52 to 15.59 & Yes & II \\
\hline Athanasiou et $a l^{2}$ & 0.70 & Not informed & 1.41 & 6 to 15 & No & Several \\
\hline $\begin{array}{l}\text { Wagner and Chung } 27 \\
\text { (girls) }\end{array}$ & 0.56 & Not informed & 1.16 & 6 to 18 & Yes & | and || \\
\hline Present study & 0.73 & 1.14 & 0.72 & 9.34 to 16.95 & Yes & ॥ \\
\hline
\end{tabular}


The findings in this study are limited by the size of the sample, bias of the treatment potential and lack of control group. Although the size of the sample is small, the highly significant probabilities obtained $(p<0.001)$ suggest that the changes observed in growth are real. Besides, additional studies with larger samples are necessary to provide better estimates of variation on transverse increase by growth. There is also the possibility of influence of the treatment subsequent to the bionator on the transverse increase although it is hardly likely that conventional fixed appliances have some potential of orthopedic effect.

\section{CONCLUSIONS}

1) The maxillary and mandibular bone bases seem to be affected by bionator therapy, during treatment, returning to a normal pattern on the posttreatment.

2) The maxillary and mandible remodeling pattern followed the same tendency of transverse growth of metallic implants.

3) With aging, the center of transverse rotation of the maxilla is displaced posteriorly.

\section{REFERENCES}

1. Marotta Araujo A, Buschang PH, Melo AC. Transverse skeletal base adaptations with Bionator therapy: a pilot implant study. Am J Orthod Dentofacial Orthop. 2004:126(6):666-71.

2. Athanasiou AE, Droschl H, Bosch C. Data and patterns of transverse dentofacial structure of 6- to 15-year-old children: a posteroanterior cephalometric study. Am J Orthod Dentofacial Orthop. 1992;101(5):465-71.

3. Baumrind S, Ben-Bassat Y, Korn EL, Bravo LA, Curry S. Mandibular remodeling measured on cephalograms: 2. A comparison of information from implant and anatomic best-fit superimpositions. Am J Orthod Dentofacial Orthop. 1992:102(3):227-38.

4. Björk A, Skieller V. Growth in width of the maxilla studied by the implant method. Scand J Plast Reconstr Surg. 1974;8(1-2):26-33.

5. Björk A, Skieller $\mathrm{V}$. Growth of the maxilla in three dimensions as revealed radiographically by the implant method. Br J Orthod. 1977;4(2):53-64

6. Björk A. Facial growth in man, studied with the aid of metallic implants. Acta Odontol Scand. 1955;13(1):9-34.

7. Björk A. Variations in growth pattern of the human mandible: Longitudinal radiographic study by the implant method. J Dent Res. 1963:42(1):400-11

8. Brieden CM, Pangrazio-Kulbersh V, Kulbersh R. Maxillary skeletal and dental change with Frankel appliances: an implant study. Angle Orthod. 1984;54(3):226-32.

9. Cortella S, Shofer FS, Ghafari J. Transverse development of the jaws: Norms for the posteroanterior cephalometric analysis. Am J Orthod Dentofacial Orthop. 1997:112(5):519-22.

10. Gandini LG Jr, Buschang PH. Maxillary and mandibular width changes studied using metallic implants. Am J Orthod Dentofacial Orthop. 2000:117(1):75-80

11. Ghafari J, Cater PE, Shofer FS. Effect of film-object distance on posteroanterior cephalometric measurements: suggestions for standardized cephalometric methods. Am J Orthod Dentofacial Orthop. 1995;108(1):30-7.

12. Gibbs SL, Hunt NP. Functional appliances and arch width. Br J Orthod. 1992:19(2):117-25

13. Hesby RM, Marshall SD, Dawson DV, Southard KA, Casko JS, Franciscus RG, et al. Transverse skeletal and dentoalveolar changes during growth. Am J Orthod Dentofacial Orthop. 2006:130(6):721-31

14. Hime DL, Owen AH 3rd. The stability of the arch-expansion effects of Fränkel appliance therapy. Am J Orthod Dentofacial Orthop. 1990;98(5):437-45.
15. Hsiao TH, Chang HP, Liu KM. A method of magnification correction for posteroanterior radiographic cephalometry. Angle Orthod. 1997:67(2):137-42

16. Işeri $H$, Solow $B$. Change in the width of the mandibular body from 6 to 23 years of age: an implant study. Eur J Orthod. 2000:22(3):229-38.

17. Korn EL, Baumrind S. Transverse development of the human jaws between the ages of 8.5 and 15.5 years, studied longitudinally with use of implants. J Dent Res. 1990;69(6):1298-306.

18. Leonardi R, Annunziata A, Caltabiano M. Landmark identification error in posteroanterior cephalometric radiography. A systematic review. Angle Orthod. 2008:78(4):761-5.

19. Lux CJ, Conradt C, Burden D, Komposch G. Dental arch widths and mandibular-maxillary base widths in Class II malocclusions between early mixed and permanent dentitions. Angle Orthod. 2003;73(6):674-85.

20. Major PW, Johnson DE, Hesse KL, Glover KE. Effect of head orientation on posterior anterior cephalometric landmark identification. Angle Orthod. 1996:66(1):51-60.

21. Major PW, Johnson DE, Hesse KL, Glover KE. Landmark identification error in posterior anterior cephalometrics. Angle Orthod. 1994;64(6):447-54.

22. Malkoc S, Sari Z, Usumez S, Koyuturk AE. The effect of head rotation on cephalometric radiographs. Eur J Orthod. 2005:27(3):315-21.

23. Owen $\mathrm{AH}$. Morphologic changes in the transverse dimension using the Fränkel appliance. Am J Orthod. 1983:83(3):200-17.

24. Savara BS, Singh IJ. Norms of size and annual increments of seven anatomical measures of maxillae in boys from three to sixteen years of age. Angle Orthod. 1968:38(2):104-20.

25. Snodell SF, Nanda RS, Currier GF. A longitudinal cephalometric study of transverse and vertical craniofacial growth. Am J Orthod Dentofacial Orthop. 1993:104(5):471-83.

26. Vargevik K. Morphologic evidence of muscle influence on dental arch width. Am J Orthod. 1979;76(1):21-8

27. Wagner DM, Chung $\mathrm{CH}$. Transverse growth of the maxilla and mandible in untreated girls with low, average, and high MP-SN angles: a longitudinal study. Am J Orthod Dentofacial Orthop. 2005;128(6):716-23.

28. Yavuz I, Ikbal A, Baydaş B, Ceylan I. Longitudinal posteroanterior changes in transverse and vertical craniofacial structures between 10 and 14 years of age. Angle Orthod. 2004;74(5):624-9. 